\title{
REPORT OF THE COMMITTEE ON SCIENCE AND ARTS ON NORBERT DE LANDTSHEER'S MACHINE FOR TREATING FLAX, HEMP, ETc.
}

\section{Hall of the Franklin Institute, ! Philiadel.Phia, Dec. 19th, 1878.}

'The Committee on Science and the Arts, constituted by the Franklin Institute of the State of Pennsylvania, to whom was referred for examination Norbert de Landtsheer's machine for treating flax, hemp and other similar plants, report that the machine occupies a floor space of about 8 by 10 feet, and consists of a cast-iron frame, a stationary feedboard or table, two pairs of fluted metal rollers, a sheet-iron drum or eylinder, furnished with blades or beaters of wood at regular intervals around its circumference, and the necessary driving pulleys, wheels, pinions and gears for automatic operation. In outward appearance it somewhat resembles a grain fan.

Two distinct operations upon the staple to be treated are performed by this maehine: the first that of breaking, the second, of scutching. The object of the first is to break the stem or "boon" forming the woody interior of the flax, or other similar fibrous plant, that this refinse may more reudily be removed in the subsequent operations. The second is to beat or "scutch" out this "boon" or broken straw, thus leaving the fibre in a condition to be mechanically divided in the heckling machine or gill-box.

In operation, the stalks of hemp or flax, which had previously undergone the process of "retting" or rotting, were placed upon the feed-table of the machine, and fed to the first pair of fluted rolls or sylinders in the direction of the fibre's length. These fluted rollers are each supported in journal-boxes, which allow the teeth or flutes to mesh, but prevents them from coming in contact at the bottom of the flutes. To these rolls or cylinders is imparted, by suitable mechanism, an alternate circular motion, forward in the direction of the scutchingdrum and backward in the direction of the feed-table, the forward motion being the greater. This, while imparting a reciprocal movement to the fibrous stalks, thus effectually breaking the "boon" or woody interior, at the same time carries the "striek" or broken portion forward to be still further operated upon by the scutchingArum or cylinder. 
This drum is of sheet-iron, affixed to cast-iron rims or spiders, is four feet in diameter and is furnished with sixteen tough wooden blades or beaters. It revolves in an opposite direction to the forward motion of the breaking rollers; that is, the upper periphery of the scutching-drum moves in the direction of the feed end of the machine, thus bringing its beaters with a downward blow against the pendant fibres, beating out the " boon" or broken woody interior. This operation is still further aided by the current of air set in motion by the revolution of the drum which winnows the chaff from the long lines of fibre.

When the stalks have been fed between the fluted rolls to a little beyond the centre of their. length the alternate circular motion is converted automatically or by hand to a rapid continuous reverse motion, which delivers to the operator who then feeds the unbroken stalk ends to the breaking rolls. These in turn undergo the above-described operations and the fibre, discharged as before, free from straw or "boon" and in straight, untangled lines.

The mechanism designed to impart the alternate circular and continuous reverse motions to the fluted rollers consists, in its essential features, of a concentric pinion-wheel brought into alternate working contact with cogs on the concave rim of a surrounding gearing and a system of crossed and open belts. This mechanical contrivance is deserving of special mention, being well adapted for the purpose designed, is capable of adjustment to suit different lengths of fibre, and may be controlled automatically or by hand.

The flax stalks opcrated upon, were grown not for the fibre, but for seed alone, and had not been properly "retted"; yet the machine under consideration performed the operations of breaking and scutehing with entire success. Flax stalks, two feet, and hemp stalks eight feet long were alternately fed to the machine and the fibre was delivered clear of "boon," straw and woody material, in from thirty to forty seconds, while but very little scutching-tow or codilla was mede.

The machine is rapid in its action, not complicated with delicate and nicely-to-be-adjusted parts, requires comparatively little power to drive and does not need skilled labor to operate it. It is a French invention, and letters patent have been granted in England and the United States, the former bearing date May 30th, 1874, and designated by No. 1900, the latter May 8th, 1877, and numbered 190,476.

The introduction and general use of this machine would without doubt tend to restore and extend the cultivation of such fibrous plants 
as flax, hemp, jute, and others of a similar nature, by enabling producers to deliver these several fibres in a clean, straight, long-line, marketable shape, at low cost.

Unlike cotton, which is comparatively a delicate plant that can only be grown profitably in the Southern and Southwestern States, flax and kindred plants may be grown readily throughout our entire country. Light soils are more suitable for its development, but good erops may be gathered from strong and clayey grond.

Hitherto the operations of breaking and scutching have been largely performed by hand. Where machinery has been used, each operation required a distinct and separate machine. Rude in vlesign and imperfect in performance, they have, even in flax-growing districts, scarcely supplanted the primitive methods, while in this country they are almost unknown.

Your sub-committee therefore respectfully submit the above, and believe this machine to be a valuable and useful improvement, worthy of award.

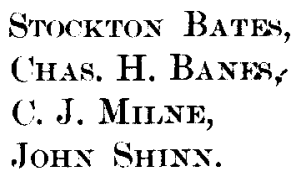

\section{FRANKLIN INSTITUTE STANDARD SCREW THREAD.}

We are in receipt of a letter from the Morse Twist Drill and Machine Co., of New Bedford, Mass., in reference to the standard for screw threads proposed by this Institute fifteen years ago. This letter we publish entire, but must venture some comments on that portion of it alluding to the difficulties to be experienced by manufacturers in originating their own standards. On page 247 will be found the assertion "If manufacturers establish their own standard, their work will not interchange either with one another or with the Government standards, by which the largest majority of the work has thus far been constructed." The so-called Government standards are the sample screws and threaded collars purchased by the Navy Department for certain of the Navy Yards. These were made by a Mr. Fox, and may or may not be correct in diameter in angle of thread or in the width of flat top and bottom. They are said to have been made according to the formulæ prepared by $\mathrm{Mr}$. 